\title{
Ultrasonographic evaluation of lung and heart in predicting successful weaning in mechanically ventilated neurosurgical patients
}

\author{
Sasidharan Sachin ${ }^{1} \cdot$ Dhritiman Chakrabarti $^{2} \cdot$ Kadarapura Nanjundaiah Gopalakrishna $^{2} \oplus \cdot$ Suparna Bharadwaj $^{2}$
}

Received: 23 May 2019 / Accepted: 8 January 2020 / Published online: 11 January 2020

(c) Springer Nature B.V. 2020

\begin{abstract}
In critically ill neurosurgical patients, delayed and premature extubation increases the risk of morbidity and mortality. Assessment of critically ill patients before and during spontaneous breathing trial (SBT) is crucial in predicting weaning failure. We explored the trend of changes with integrated lung and cardiac ultrasonography in predicting success of weaning in neurosurgical patients. Lung ultrasound and cardiac ultrasound was performed before and after $30 \mathrm{~min}$ and $120 \mathrm{~min}$ of SBT. Lung ultrasound score (LUS, range 0-36) was calculated using a predefined method of assessment of six chest regions on either side. The left ventricular function was evaluated by measuring fractional area change. The maximum velocities of mitral inflow $\mathrm{E}$ and $\mathrm{A}$ waves (E/A), deceleration time of $\mathrm{E}$ wave (DTE) and tissue doppler based $\mathrm{E}^{\prime}$ wave at lateral annulus to calculate $\mathrm{E} / \mathrm{E}^{\prime}$, were measured to assess left ventricular filling pressure. Twenty seven patients underwent SBT, among these 22 had success and five had failure of SBT. The SBT failure group had higher baseline LUS and progressively higher LUS during SBT compared to the success group, suggesting significant lung de-recruitment. There was significant increase in the LV filling pressure (increase E/A and E/E', decrease in DTE) after 30 and $120 \mathrm{~min}$ of SBT in failure group compared to the success group. Point of care lung and cardiac ultrasonography may be useful in detecting cardiopulmonary changes induced by SBT. Higher lung aeration loss and LV filling pressure were observed with SBT failure group.
\end{abstract}

Keywords Lung ultrasound $\cdot$ Weaning $\cdot$ Echocardiography $\cdot$ Spontaneous breathing trial $\cdot$ Neurosurgical

\section{Introduction}

Prediction of weaning failure, particularly in neurosurgical patients is challenging. Delayed weaning and extubation in acute brain injured patients increases the rate of mortality and prolongs length of stay in intensive care unit (ICU) [1]. Similarly, early attempts of weaning are complicated by post-extubation respiratory dysfunction and reintubation, associated with increased mortality, higher rate of tracheostomy, increased duration of ventilatory support and prolonged length of ICU stay $[2,3]$. The common reasons for endotracheal intubation and mechanical ventilation in neurosurgical patients include impaired neurological function,

Kadarapura Nanjundaiah Gopalakrishna gops868@gmail.com

1 Daya General Hospital and Speciality Surgical Centre, Peringavu, Thrissur, Kerala 680022, India

2 Department of Neuroanaesthesia and Neurocritical Care, National Institute of Mental Health and Neuro Sciences (NIMHANS), Bangalore 560 029, India airway protection or raised intracranial pressure, in addition to cardiorespiratory abnormalities. The primary aim of care for these patients is to detect and prevent any secondary neurological insult while supporting systemic and neurological homeostasis. Hypoxia and hypercarbia are factors which need to be absolutely avoided while caring for such patients. Mechanical ventilation is continued until the patient is clinically stabilized and primary neurological damage has been taken care. Subsequently the transition from control ventilation to spontaneous ventilation begins $[4,5]$.

Literature suggests that Glasgow coma scale (GCS) of 8 or above and presence of adequate cough reflex are more likely to predict successful extubation in neurosurgical patients. These data also suggest that complete neurological recovery is not necessary to execute successful extubation $[6,7]$. The aetiology for weaning failure from ventilatory support is usually multifactorial, involving composite interaction between cardiac and lung function. In ICU, utility of numerous respiratory indices to guide weaning process have been replaced by spontaneous breathing trial (SBT) $[8$, 9]. Apart from loss of lung aeration due to transition from 
prolonged mechanical ventilation to spontaneous breathing, there is increase LV preload and after load, and decrease in LV compliance. These factors may increase LV filling pressure leading to failure of weaning $[10,11]$.

To enhance the success of weaning, apart from the clinical assessment, ultrasonic evaluation of cardiorespiratory system before and during SBT is very important in anticipating weaning failure [12]. Assessment of lung aeration by ultrasonography is rapidly gaining significance in weaning protocol [13]. Apart from lung ultrasonography, the role of transthoracic echocardiography in successfully predicting weaning capability has been investigated in the recent times [14]. Cardiac related weaning failure may be due to systolic LV dysfunction or isolated diastolic dysfunction representing nearly $40 \%$ of all failed weaning $[15,16]$ The aim of this prospective observational study was to evaluate the cardiorespiratory ultrasonographic parameters in patients being weaned and contrasting the trend of changes in those successfully completing SBT in comparison to SBT failure.

\section{Methods}

This prospective observational study was conducted over a 6 month period (from December 2017 to May 2018) after obtaining approval from the institute ethics committee (IEC). Informed consent was obtained from patients next of kin. This trial was registered in clinical trial registry with ClinicalTrials.gov Identifier: NCT03580993. Consecutive adult neurosurgical patients (age $>18$ years) who were mechanically ventilated for longer than $48 \mathrm{~h}$ and planned for weaning were recruited. Inclusion in the study was allowed when patients' underlying disease that required mechanical ventilation was considered reversed or stabilised by the attending physician, rendering them eligible for SBT. Exclusion criteria included age less than 18 years, Pregnancy, GCS score less than 8 , pre-weaning $\mathrm{PaO}_{2} / \mathrm{FiO}_{2}$ ratio of less than 200, severe ICU acquired neuromyopathy, lower cranial nerve involvement, tracheostomized patients, patients with high spinal cord lesions (above T8), presence of thoracostomy, pneumothorax or pneumomediastinum or pleural effusion, presence of rib fractures, patients having severe left ventricular dysfunction $(\mathrm{LVEF}<35 \%)$, valvular heart disease and patients with planned prophylactic noninvasive ventilation. Secondary exclusion criteria consisted of uncooperative patient behavior or absence of a proper ultrasonographic window allowing adequate visualization of the lung or the heart.

\subsection{Protocol}

For every patient, standard medical care was provided by the ICU physician in charge. Discontinuation from mechanical ventilation/weaning was attempted according to clinical judgment of the intensivist. The treating physician was blind to the ultrasound results.

\subsection{Spontaneous breathing trial}

When the patient was deemed ready for SBT, they were allowed to breathe spontaneously through a T-tube circuit with oxygen flow at $5 \mathrm{~L} / \mathrm{min}$ for $1 \mathrm{~h}$ during the first SBT. Subsequent time of weaning was determined by the treating physician.

SBT failure was defined as inability to tolerate a T-piece trial for 30 to $120 \mathrm{~min}$ [17]. Criteria for failure to tolerate SBT consisted of the following:

a. Change in level of consciousness

b. Clinical features of respiratory distress (Respiratory rate $>35$ breaths/min, arterial oxygen saturation $<90 \%$, paradoxical thoracoabdominal breathing or use of accessory respiratory muscles)

c. Haemodynamic instability (heart rate $>140$, systolic blood pressure $<90 \mathrm{mmHg}$ or $20 \%$ change from baseline)

Patients with SBT failure were put back on controlled ventilatory mode. Patients who underwent successful SBT were continued with the weaning protocol. The successful SBT patients were monitored for extubation failure. Criteria for failed extubation included patient requiring either reintubation or non-invasive ventilation or high-flow nasal oxygen therapy within $48 \mathrm{~h}$ following extubation [18].

The lung ultrasound and echocardiographic parameters including haemodynamics were measured and documented during the following time points:

(1) Before SBT

(2) 30 min after initiating SBT

(3) 120 min after SBT

\subsection{Lung ultrasonography}

Lung ultrasonography was performed by a trained investigator using 2-4 MHz probe (Esaote ultrasound system, MyLab $^{\mathrm{TM}}$ Gamma, Genova, Italy). Each intercostal space of upper and lower parts of the anterior, lateral, and posterior regions of the left and right chest wall was examined [19]. Four ultrasound lung aeration patterns were defined:

1. Normal lung aeration (N): Lung sliding present with A-lines/ less than two isolated B lines.

2. Moderate loss of lung aeration (B1 lines): multiple welldefined B lines. 
3. Severe loss of lung aeration (B2 lines): multiple coalescent B lines.

4. Lung consolidation (C): Tissue pattern characterized by dynamic air bronchograms.

For a given region of interest, points were allocated according to the worst ultrasound pattern observed: $\mathrm{N}=0$, B1 lines $=1, \mathrm{~B} 2$ lines $=2, \mathrm{C}=3$. The Lung ultrasound score (LUS) ranging between 0 and 36 was calculated as the sum of the points $[13,20]$.

\subsection{Transthoracic echocardiography}

All of the patients underwent transthoracic echocardiographic examination by $2.5-3.5 \mathrm{MHz}$ cardiac probe. The left ventricle systolic function was assessed by measuring fractional area change (FAC) in the short axis view of the left ventricle. Left ventricle diastolic function assessed by placing pulsed wave doppler at tip of mitral leaflets, we recorded maximal flow velocity during early diastole ( $\mathrm{E}$ wave) and late diastole (A wave), to measure the ratio of mitral inflow velocity (E/A ratio) and deceleration time of $\mathrm{E}$ wave. Doppler tissue imaging (DTI) was used to calculate $\mathrm{E}^{\prime}$ at the lateral mitral annulus and assess left ventricular (LV) filling pressure by measuring $\mathrm{E} / \mathrm{E}^{\prime}$ ratio [21].

\subsection{Statistical analysis}

Data was collated offline in a Microsoft Excel spreadsheet (ver. 2007). Analysis was conducted using R software (ver. 3.5.2) [22]. Interval scale variables are represented as medians and inter-quartile ranges, and categorical data as frequencies and proportions. Demographic data and single time point variables were compared between the groups using Mann-Whitney U-test (in view of small sample size) for interval scale data and using Chi-square test or Fisher test (as appropriate) for categorical data. It was found that age and chronic obstructive pulmonary disease (COPD) was significantly different for the outcome groups of successful/ failure SBT. However, due to small sample size, and complete separation of outcome with inclusion of confounding covariates, regression analysis could not be conducted. Non parametric longitudinal design analysis using rank method was conducted using "nparLD" package of R for between group hypothesis testing of repeated measures data (Pre SBT, $30 \mathrm{~min}$ SBT and $120 \mathrm{~min}$ SBT time points) [23]. $\mathrm{p}<0.05$ was taken as level for statistical significance.

\section{Results}

Thirty patients were assessed for inclusion into the study. Three patients had neurological deterioration and were excluded. Twenty-seven patients were included and underwent SBT ( success $=22$, failure $=5$ ). Among 22 SBT success patients, 4 (18.1\%) had extubation failure.

\subsection{Demographic variables}

Age and proportion of COPD were found to be significantly different for SBT success and failure groups (Table 1).

\subsection{Lung ultrasound score (LUS)}

Baseline LUS were found to be significantly higher in SBT failure group compared to success group $(p=0.007$, Table 2). LUS was found to increase during the course of SBT in both the groups (Table 2, Fig. 1) and the increase was found to be statistically significant $(\mathrm{p}<0.001$ for both groups). Overall between group comparison was found to be statistically significant $(\mathrm{p}<0.001)$, which probably builds up on the baseline difference. Group*Time interaction (difference of trend of change of LUS over time, compared between the two groups) was not found to be significantly different $(\mathrm{p}=0.866)$.

\subsection{Haemodynamic parameters}

There was no difference of baseline heart rate (HR), systolic and diastolic blood pressures (SBP, DBP) between two groups (Table 2). Within group effect showed a statistically significant increase of HR in both the groups (Table 2 , Fig. 1), Blood pressures did not change significantly in the SBT success group, while they increased in the SBT failure group. Interaction effect was found to be statistically significant for all the hemodynamic variables, showing a higher rate of change in the failure group compared to the success group. Since interaction effect was found significant, between group effect will not be discussed.

Table 1 Presents distribution of demographic variables between SBT groups

\begin{tabular}{llll}
\hline Variable & SBT success & SBT failure & p-value \\
\hline Age (mean \pm SD) & $44.5 \pm 12.1$ & $55.4 \pm 5.7$ & 0.04 \\
Sex (F/M) & $9 / 13$ & $0 / 5$ & 0.136 \\
CAD (absent/present) & $20 / 2$ & $4 / 1$ & 0.474 \\
COPD (absent/present) & $22 / 0$ & $2 / 3$ & 0.003 \\
VAP (absent/present) & $19 / 3$ & $5 / 0$ & 1 \\
Inotropes (absent/present) & $16 / 6$ & $2 / 3$ & 0.295 \\
\hline
\end{tabular}

$S B T$ spontaneous breathing trial, $C A D$ coronary artery disease, $C O P D$ chronic obstructive pulmonary disease, $V A P$ ventilator associated pneumonia, $F$ female, $M$ male, $S D$ standard deviation $\mathrm{p}<0.05$ is level of statistical significance 
Table 2 Table depicts p-values for between and within group comparisons of LUS, echocardiographic parameters and haemodynamic parameters between the SBT success and failure groups

\begin{tabular}{|c|c|c|c|c|c|}
\hline Variable & SBT & $\begin{array}{l}\text { Pre SBT } \\
\text { comparison }\end{array}$ & Within group effect & $\begin{array}{l}\text { Between } \\
\text { group effect }\end{array}$ & $\begin{array}{l}\text { Group*time } \\
\text { interaction } \\
\text { effect }\end{array}$ \\
\hline LUS & $\begin{array}{l}\text { Failure } \\
\text { Success }\end{array}$ & 0.007 & $\begin{array}{l}<0.001 \\
<0.001\end{array}$ & $<0.001$ & 0.866 \\
\hline $\mathrm{FAC}(\%)$ & $\begin{array}{l}\text { Failure } \\
\text { Success }\end{array}$ & 0.333 & $\begin{array}{r}<0.001 \\
0.263\end{array}$ & 0.31 & 0.108 \\
\hline $\mathrm{E} / \mathrm{E}^{\prime}$ & $\begin{array}{l}\text { Failure } \\
\text { Success }\end{array}$ & 0.731 & $\begin{array}{l}0.002 \\
0.012\end{array}$ & 0.13 & 0.136 \\
\hline $\mathrm{E} / \mathrm{A}$ & $\begin{array}{l}\text { Failure } \\
\text { Success }\end{array}$ & 0.16 & $\begin{array}{r}<0.001 \\
0.608\end{array}$ & 0.46 & $<0.001$ \\
\hline DTE (ms) & $\begin{array}{l}\text { Failure } \\
\text { Success }\end{array}$ & 0.126 & $\begin{array}{r}<0.001 \\
0.078\end{array}$ & 0.639 & 0.007 \\
\hline HR & $\begin{array}{l}\text { Failure } \\
\text { Success }\end{array}$ & 0.397 & $\begin{array}{l}<0.001 \\
<0.001\end{array}$ & 0.015 & 0.02 \\
\hline $\mathrm{SBP}(\mathrm{mmHg})$ & $\begin{array}{l}\text { Failure } \\
\text { Success }\end{array}$ & 0.875 & $\begin{array}{l}0.001 \\
0.281\end{array}$ & 0.322 & 0.009 \\
\hline $\mathrm{DBP}(\mathrm{mmHg})$ & $\begin{array}{l}\text { Failure } \\
\text { Success }\end{array}$ & 0.706 & $\begin{array}{l}0.001 \\
0.276\end{array}$ & 0.053 & 0.014 \\
\hline
\end{tabular}

Pre SBT comparison shows results of Mann-Whitney U test, and the other columns show results of nonparametric longitudinal design analysis

$S B T$ spontaneous breathing trial, LUS lung ultrasound score, SBP systolic blood pressure, DBP diastolic blood pressure, $H R$ heart rate, $F A C$ fractional area change, $E$ doppler mitral early diastolic wave, $A$ doppler mitral late diastolic wave, DTE deceleration time of $\mathrm{E}$ wave, $E^{\prime}$ tissue doppler based early diastolic wave at lateral annulus

$\mathrm{p}<0.05$ is taken as level of statistical significance

\subsection{Parameters of diastolic cardiac function}

Baseline values of $\mathrm{E} / \mathrm{E}^{\prime}$ ratio, $\mathrm{E} / \mathrm{A}$ ratio and DTE did not show any difference between the two groups (Table 2). SBT failure group registered statistically significant increases in $\mathrm{E} / \mathrm{E}^{\prime}$ ratio and E/A ratio, and reduction in DTE (Table 2, Fig. 2). In the SBT success group, $E / E^{\prime}$ ratio was found to increase slightly $(p=0.012)$, while E/A ratio and DTE stayed relatively constant over the time points. Interaction effect was found to be statistically significant for E/A ratio and DTE ( $p<0.001$ and $p=0.007$ respectively), and trending towards significance for $E / E^{\prime}$ ratio $(p=0.136)$. Between group effect for $\mathrm{E} / \mathrm{E}^{\prime}$ ratio was not found to be statistically significant.

\subsection{Fractional area change (FAC)}

Baseline FAC was not found to be significantly different between the two groups $(p=0.333)$. FAC decreased significantly in the SBT failure group ( $<<0.001$, Table 2, Fig. 2), while SBT success group registered no change $(p=0.263)$. Between group effect was not found to be statistically significant, while interaction effect was found to be trending towards significance $(p=0.108)$. The same is probably due to small sample size and explained by the within group changes discussed above.

Table of descriptives for all variables is provided as a separate table (Table 3).

\section{Discussion}

The reasons for weaning failure from ventilatory support are usually multifactorial and include complex interaction between cardiac and respiratory dysfunction [17]. We present trend of changes in lung ultrasound findings and echocardiographic cardiac status during SBT. Brisk dynamic changes in the pulmonary and cardiac load taking place throughout the SBT can be picked up by cardiopulmonary sonography in real time. In our study SBT failure group had higher basal LUS ( $p=0.007$, Table 2$)$ and progressively increasing LUS at $30 \mathrm{~min}$ and at end of SBT denoting significant lung de-recruitment (Fig. 1). There was no difference in the LV filling pressure before SBT between success and failure groups (Table 2), but there was significant increase in the $\mathrm{LV}$ filling pressure (increase $\mathrm{E} / \mathrm{A}$ and $\mathrm{E} / \mathrm{E}^{\prime}$, decrease in DTE) after 30 and 120 min of SBT in failure group compared to the success group (Table 2, Fig. 2). In our trial none of the patients had LV systolic dysfunction before or at the 
Fig. 1 Depicting trend of change of LUS and hemodynamic variables over SBT time points. $S B T$ spontaneous breathing trial, LUS lung ultrasound score, $S B P$ systolic blood pressure, $D B P$ diastolic blood pressure, $H R$ heart rate
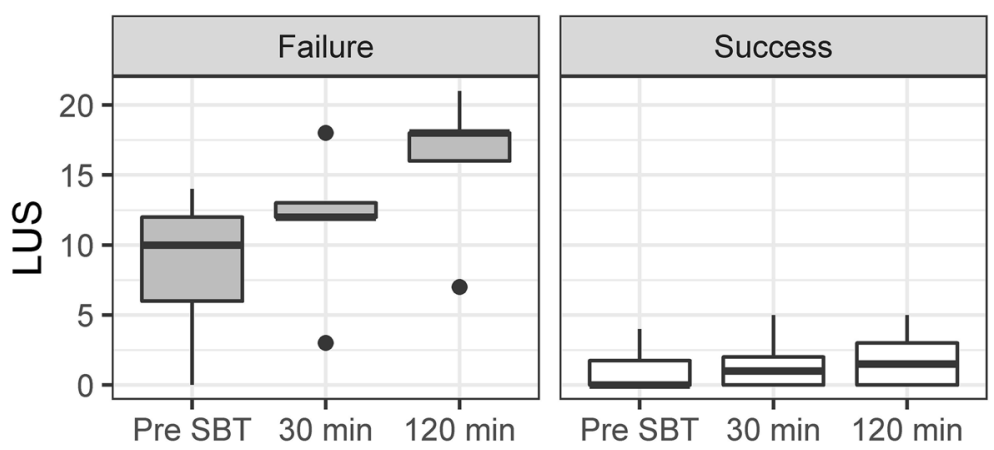

SBT

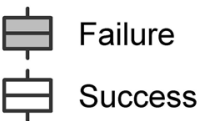

SBT Time Points

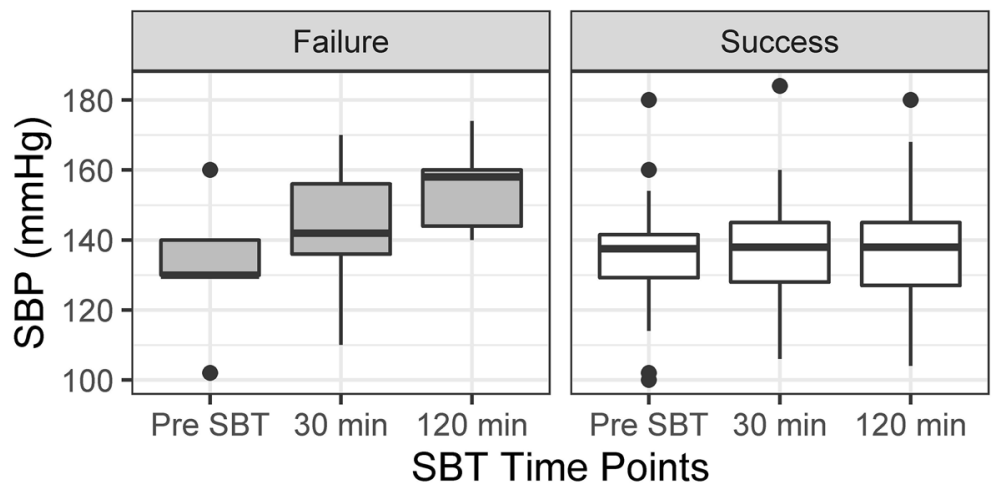

SBT
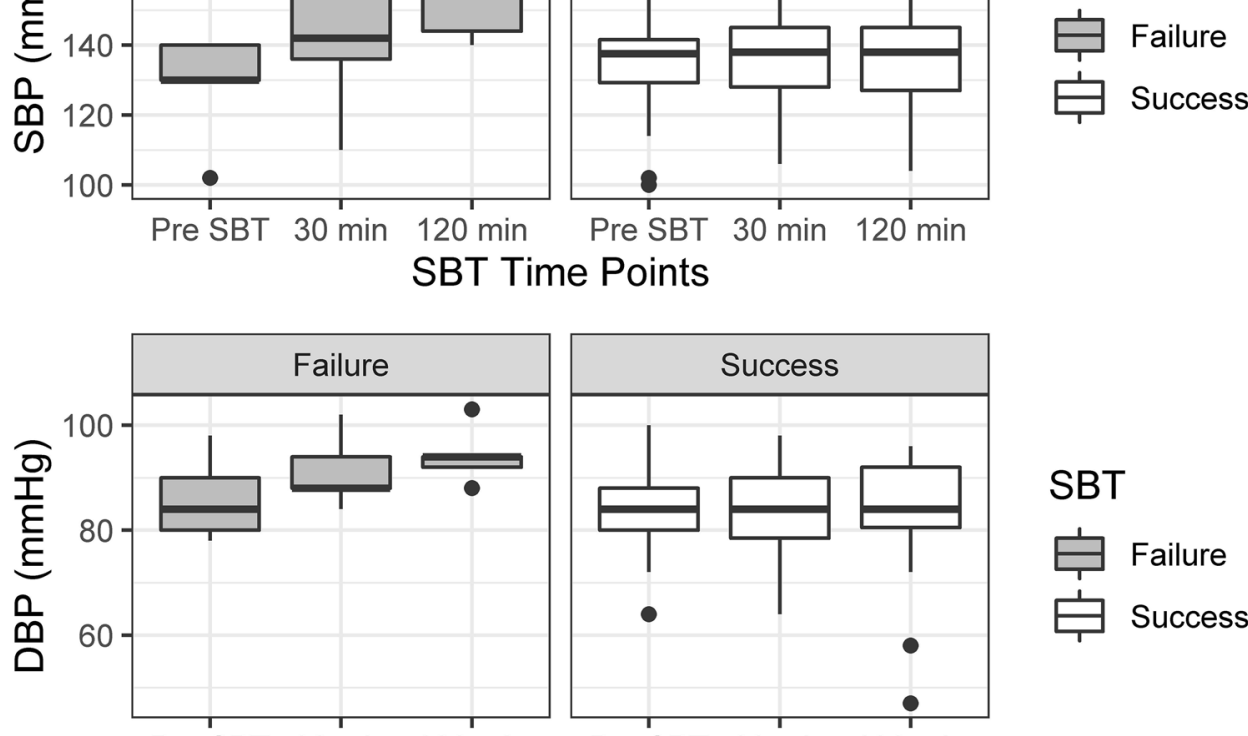

Pre SBT $30 \mathrm{~min} 120 \mathrm{~min}$

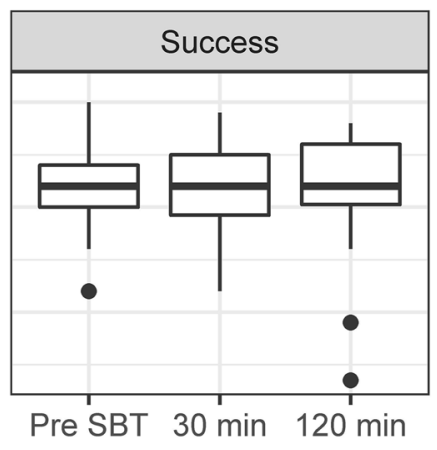

SBT

Failure

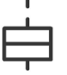

Success

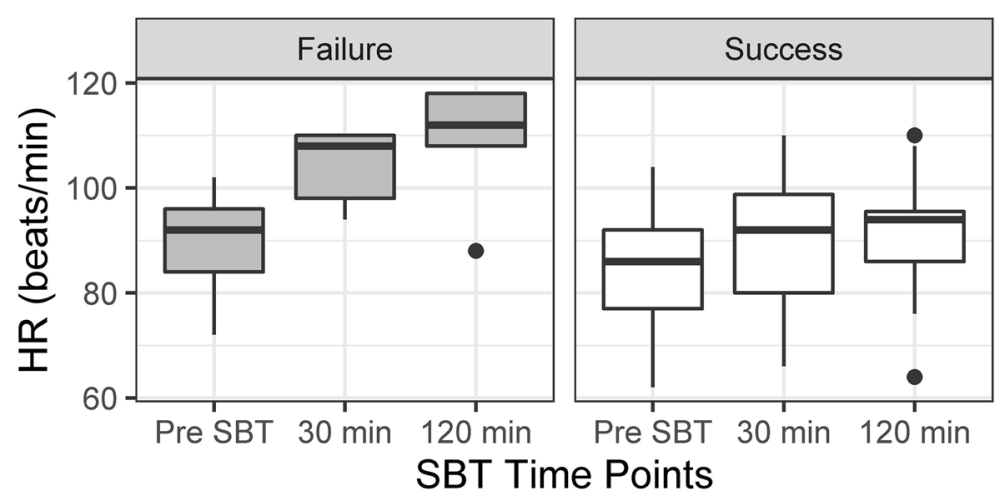

SBT

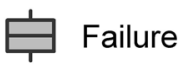

Success

end of SBT, but there was decreasing trend of FAC in the SBT failure group. (Table 2, Fig. 2).

Increase in LUS leading to significant de-recruitment and increase in LV filling pressure may have cumulatively contributed to failure of SBT. It is difficult to differentiate incidence of cardiac or pulmonary related weaning failure, because the increase in cardiac and pulmonary load are strongly interconnected [24]. In a study by Soummer [13], 
Fig. 2 Depicting trend of change of echocardiographic variables over SBT time points. $F A C$ fractional area change, $S B T$ spontaneous breathing trial, $E$ doppler mitral early diastolic wave, $A$ doppler mitral late diastolic wave, DTE deceleration time of E wave, $E^{\prime}$ tissue doppler based early diastolic wave at lateral annulus
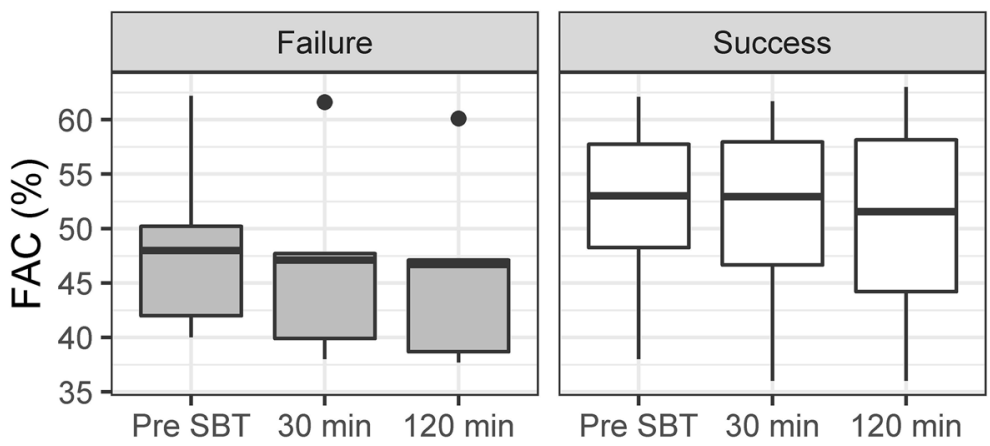

SBT

SBT Time Points
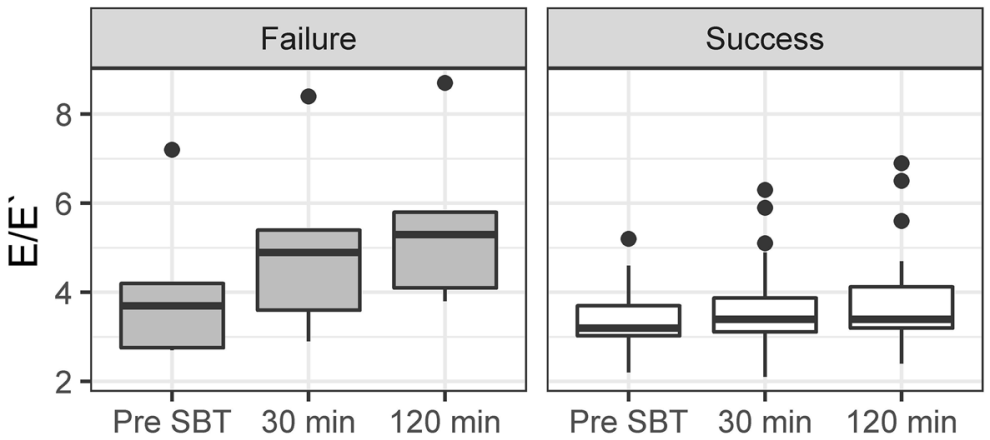

SBT

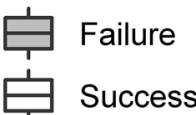

\section{SBT Time Points}
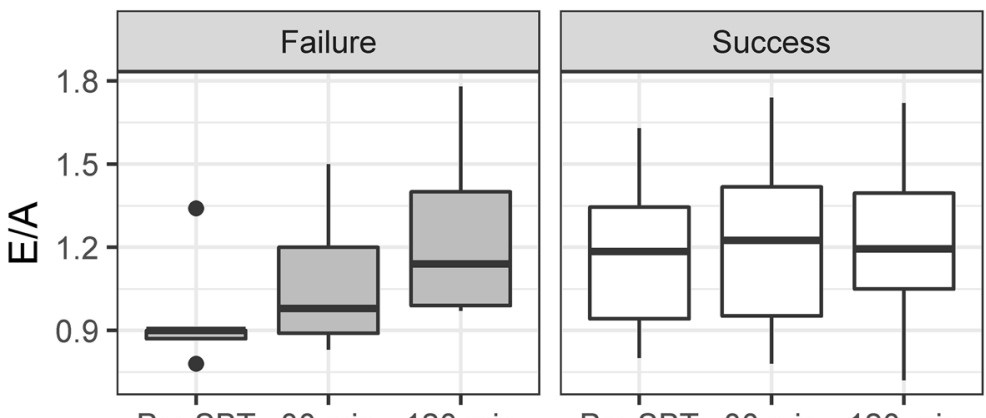

SBT

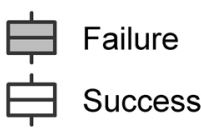

Pre SBT $30 \mathrm{~min} 120 \mathrm{~min}$

SBT Time Points

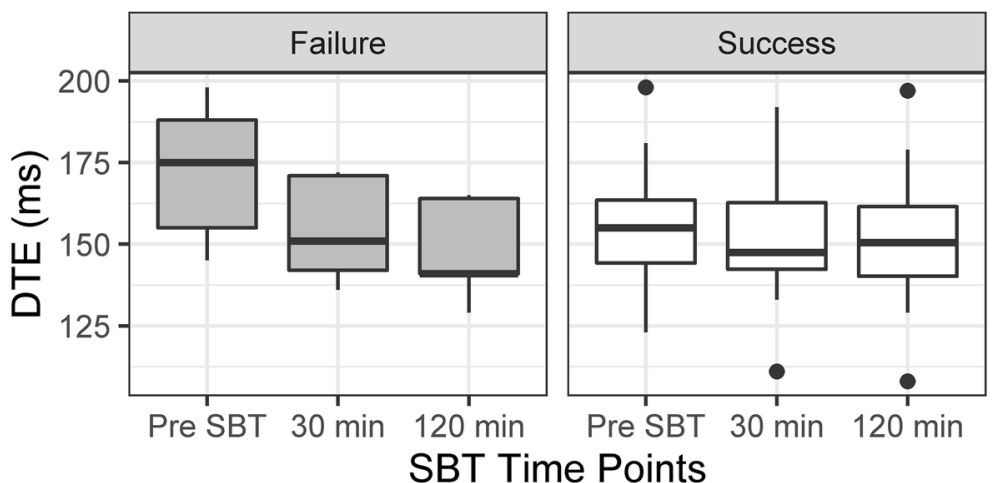

SBT

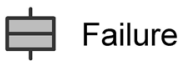

Success patients with lower LUS had better aeration and patients with progressive higher LUS during SBT had progressive lung de-recruitment. Initiation of weaning in our study was based on a clinical decision of treating intensivist, assuming that the respiratory condition has been optimally stabilised. However, without objective evidence, the process of weaning may be initiated far before normalization of pulmonary function. SBT failure or extubation failure is likely due to 
Table 3 Depicting descriptives of all variables across the SBT time points [median (interquartile range)]

\begin{tabular}{lllll}
\hline Variable & Group & Pre SBT & 30 min of SBT & 120 min of SBT \\
\hline LUS & Failure & $10(6-12)$ & $12(12-13)$ & $18(16-18)$ \\
& Success & $0(0-1.75)$ & $1(0-2)$ & $1.5(0-3)$ \\
FAC $(\%)$ & Failure & $48(42-50.2)$ & $47.1(39.9-47.7)$ & $46.7(38.7-47.1)$ \\
& Success & $53(48.25-57.75)$ & $52.95(46.7-58)$ & $51.55(44.2-58.2)$ \\
E/E' & Failure & $3.7(2.76-4.2)$ & $4.9(3.6-5.4)$ & $5.3(4.1-5.8)$ \\
& Success & $3.2(3.03-3.7)$ & $3.4(3.1-3.9)$ & $3.4(3.2-4.1)$ \\
E/A & Failure & $0.9(0.87-0.9)$ & $0.98(0.89-1.2)$ & $1.14(0.99-1.4)$ \\
& Success & $1.2(0.94-1.34)$ & $1.2(0.95-1.4)$ & $1.2(1.05-1.4)$ \\
DTE (ms) & Failure & $175(155-188)$ & $151(142-171)$ & $141(141-164)$ \\
& Success & $155(144.3-163.5)$ & $147.5(142.3-162.8)$ & $150.5(140.2-161.5)$ \\
HR & Failure & $92(84-96)$ & $108(98-110)$ & $112(108-118)$ \\
& Success & $86(77-92)$ & $92(80-98.75)$ & $94(86-95.5)$ \\
SBP $(\mathrm{mmHg})$ & Failure & $130(130-140)$ & $142(136-156)$ & $158(144-160)$ \\
& Success & $137.5(129.25-141.5)$ & $138(128-145)$ & $138(127-145)$ \\
DBP $(\mathrm{mmHg})$ & Failure & $84(80-90)$ & $88(88-94)$ & $94(92-94)$ \\
& Success & $84(80-88)$ & $84(78.5-90)$ & $84(80.5-92)$ \\
\hline
\end{tabular}

SBT spontaneous breathing trial, LUS lung ultrasound score, $S B P$ systolic blood pressure, $D B P$ diastolic blood pressure, $H R$ heart rate, $F A C$ fractional area change, $E$ doppler mitral early diastolic wave, $A$ doppler mitral late diastolic wave, DTE deceleration time of $\mathrm{E}$ wave, $E^{\prime}$ tissue doppler based early diastolic wave at lateral annulus inadequate lung reaeration at the time of SBT. Lung ultrasonography provides a reliable method to estimate regional aeration of lung $[19,20]$. Literature suggests transition from mechanical ventilation to spontaneous breathing is linked with increased cardiac preload and after load [14, 25]. Similar to our study results, literature suggests there are significant changes in doppler mitral flow indexes (increase in E/A, $\mathrm{E} / \mathrm{E}^{\prime}$ and decrease in DTE) following initiation of SBT, suggesting increase in left ventricular filling pressure $[14,26]$. Integrative use of cardiothoracic chest ultrasound data may help in predicting SBT failure or post extubation distress in critically ill patients [27, 28].

During SBT, success group had more stable blood pressure, while the failure group had progressive increase in heart rate and blood pressure. This may be due to a reflex mechanism to compensate for imbalance in cardiopulmonary load during SBT [29]. Patients with higher age and presence of COPD were more likely to have SBT failure in our series. In a study by Asehnoune et al. [30], age more than 40 years in severe brain injured patients was one of the predictors for weaning failure. Also, weaning failure has been shown to be common in patients with COPD [17, 31].

Extubation failure may occur despite successful SBT due to other causes such as upper airway obstruction due to airway oedema, inability to handle excessive secretion, neurological impairment and inadequate muscle strength. In this series $18.1 \%$ of SBT success patients had extubation failure. Reasons for reintubation included neurological deterioration $(\mathrm{n}=2)$ and inability of the patient to manage excessive secretions after extubation $(n=2)$. Currently, indices intended to predict SBT failure are indirect evidence of loss of lung aeration such as oxygen saturation defect, tachypnoea to compensate minute ventilation, altered mental status, tachycardia and hemodynamic instability [24]. Direct assessment of regional lung aeration provides a major advantage in predicting SBT success. Lung ultrasound has replaced conventional radiological means of assessing lung aeration, because it is point of care, easily repeatable, non-invasive and highly predictable [20, 32]. Several trials have shown utility of lung ultrasound for lung re-aeration following antimicrobial therapy in ventilator associated pneumonia (VAP) [33], assessing positive end-expiratory pressure (PEEP) and prone position induced lung recruitment [20] and resolution of pulmonary oedema [34]. Lung ultrasound based detection of SBT induced de-recruitment may not elicit the cause for aeration loss. The other probable factors involved in SBT induced lung aeration loss like fluid overload, massive pleural effusion, pulmonary infection, cardiac dysfunction, copious bronchial secretions and diaphragmatic dysfunction should be screened simultaneously and managed accordingly.

\section{Limitation}

This is a single institution, observational study with small sample size, which limits generalizability of the findings. Before generalising the results of this study, a randomized, multicentre interventional study is required to assess the impact of combined cardiothoracic chest ultrasound 
monitoring during SBT. In this study a single investigator performed ultrasound examination who had 12 months experience in lung cardiac ultrasound. Trials have shown the learning curve for gaining skills in chest ultrasonography ranges from 3 weeks to 7 months based on the expertise level [35-37]. In SBT failure group, we were unable to differentiate the major contributor-lung aeration loss or increased LV filling pressure or a combined effect. The criteria for failure to tolerate SBT was based on clinical judgement (parameters include change of level of consciousness, clinical features of respiratory distress, and haemodynamic instability). Another objective assessment determining failure of SBT, like arterial blood gas analysis was not used in this study during SBT. We did not evaluate biological markers of cardiovascular system during SBT like circulating B-type and atrial natriuretic peptides (BNP, ANP) to predict weaning success [11].

\section{Conclusion}

Bedside lung and cardiac sonographic examination before and during SBT may help in predicting success of SBT. Higher LUS, E/A, E/E' ratios and lower DTE were observed in patients who failed SBT. Larger studies using this modality as a guiding tool for SBT are required to confirm these findings.

\section{References}

1. Coplin WM, Pierson DJ, Cooley KD, Newell DW, Rubenfeld GD. Implications of extubation delay in brain-injured patients meeting standard weaning criteria. Am J Respir Crit Care Med. 2000;161(5):1530-6. https://doi.org/10.1164/ajrccm.161.5.99051 02 .

2. Torres A, Gatell JM, Aznar E, El-Ebiary M, Puig de la Bellacasa J, Gonzalez J, Ferrer M, Rodriguez-Roisin R. Re-intubation increases the risk of nosocomial pneumonia in patients needing mechanical ventilation. Am J Respir Crit Care Med. 1995;152(1):137-41. https://doi.org/10.1164/ajrccm.152.1.75998 12.

3. Epstein SK, Ciubotaru RL, Wong JB. Effect of failed extubation on the outcome of mechanical ventilation. Chest. 1997;112(1):186-92.

4. Lazaridis C, DeSantis SM, McLawhorn M, Krishna V. Liberation of neurosurgical patients from mechanical ventilation and tracheostomy in neurocritical care. J Crit Care. 2012;27(4):417. e411-418. https://doi.org/10.1016/j.jcrc.2011.08.018.

5. Juern JS. Removing the critically ill patient from mechanical ventilation. Surg Clin North Am. 2012;92(6):1475-83. https://doi. org/10.1016/j.suc.2012.08.008

6. Namen AM, Ely EW, Tatter SB, Case LD, Lucia MA, Smith A, Landry S, Wilson JA, Glazier SS, Branch CL, Kelly DL, Bowton DL, Haponik EF. Predictors of successful extubation in neurosurgical patients. Am J Respir Crit Care Med. 2001;163(3 Pt 1):658-64. https://doi.org/10.1164/ajrccm.163.3.2003060.
7. Navalesi P, Frigerio P, Moretti MP, Sommariva M, Vesconi S, Baiardi P, Levati A. Rate of reintubation in mechanically ventilated neurosurgical and neurologic patients: evaluation of a systematic approach to weaning and extubation. Crit Care Med. 2008;36(11):2986-92. https://doi.org/10.1097/CCM.0b013 e31818b35f2.

8. Macintyre NR. Evidence-based assessments in the ventilator discontinuation process. Respir Care. 2012;57(10):1611-8. https://doi.org/10.4187/respcare.02055.

9. Tanios MA, Nevins ML, Hendra KP, Cardinal P, Allan JE, Naumova EN, Epstein SK. A randomized, controlled trial of the role of weaning predictors in clinical decision making. Crit Care Med. 2006;34(10):2530-5. https://doi.org/10.1097/01. ccm.0000236546.98861.25.

10. Lemaire F, Teboul JL, Cinotti L, Giotto G, Abrouk F, Steg G, Macquin-Mavier I, Zapol WM. Acute left ventricular dysfunction during unsuccessful weaning from mechanical ventilation. Anesthesiology. 1988;69(2):171-9.

11. Ait-Oufella H, Tharaux PL, Baudel JL, Vandermeersch S, Meyer P, Tonnellier M, Dussaule JC, Guidet B, Offenstadt G, Maury E. Variation in natriuretic peptides and mitral flow indexes during successful ventilatory weaning: a preliminary study. Intensive Care Med. 2007;33(7):1183-6. https://doi.org/10.1007/s0013 4-007-0627-x.

12. Mayo P, Volpicelli G, Lerolle N, Schreiber A, Doelken P, Vieillard-Baron A. Ultrasonography evaluation during the weaning process: the heart, the diaphragm, the pleura and the lung. Intensive Care Med. 2016;42(7):1107-17. https://doi. org/10.1007/s00134-016-4245-3.

13. Soummer A, Perbet S, Brisson H, Arbelot C, Constantin JM, Lu Q, Rouby JJ. Ultrasound assessment of lung aeration loss during a successful weaning trial predicts postextubation distress*. Crit Care Med. 2012;40(7):2064-72. https://doi.org/10.1097/ CCM.0b013e31824e68ae.

14. Lamia B, Maizel J, Ochagavia A, Chemla D, Osman D, Richard C, Teboul JL. Echocardiographic diagnosis of pulmonary artery occlusion pressure elevation during weaning from mechanical ventilation. Crit Care Med. 2009;37(5):1696-701. https://doi. org/10.1097/CCM.0b013e31819f13d0.

15. Teboul JL, Monnet X, Richard C. Weaning failure of cardiac origin: recent advances. Crit Care. 2010;14(2):211. https://doi. org/10.1186/cc8852.

16. Teboul JL. Weaning-induced cardiac dysfunction: where are we today? Intensive Care Med. 2014;40(8):1069-79. https://doi. org/10.1007/s00134-014-3334-4.

17. Antonio ACP, Teixeira C, Castro PS, Savi A, Maccari JG, Oliveira RP, Knorst MM. Behavior of lung ultrasound findings during spontaneous breathing trial. Rev Bras Ter Intensiva. 2017;29(3):279-86. https://doi.org/10.5935/0103-507x.20170 038.

18. Karanjia N, Nordquist D, Stevens R, Nyquist P. A clinical description of extubation failure in patients with primary brain injury. Neurocrit Care. 2011;15(1):4-12. https://doi.org/10.1007/s1202 8-011-9528-5.

19. Bouhemad B, Zhang M, Lu Q, Rouby JJ. Clinical review: bedside lung ultrasound in critical care practice. Crit Care. 2007;11:205. https://doi.org/10.1186/cc5668.

20. Bouhemad B, Brisson H, Le-Guen M, Arbelot C, Lu Q, Rouby JJ. Bedside ultrasound assessment of positive end-expiratory pressure-induced lung recruitment. Am J Respir Crit Care Med. 2011;183(3):341-7. https://doi.org/10.1164/rccm.201003-0369O C.

21. Boussuges A, Blanc P, Molenat F, Burnet H, Habib G, Sainty JM. Evaluation of left ventricular filling pressure by transthoracic Doppler echocardiography in the intensive care unit. Crit Care Med. 2002;30(2):362-7. 
22. R Core Team (2018) R: A language and environment for statistical computing. R Foundation for Statistical Computing, Vienna, Austria. https://www.R-project.org/. Accessed 24 Mar 2019

23. Noguchi K, Gel YR, Brunner E, Konietschke F. nparLD: an R software package for the nonparametric analysis of longitudinal data in factorial experiments. J Stat Softw. 2012;50(12):1-23.

24. Boles JM, Bion J, Connors A, Herridge M, Marsh B, Melot C, Pearl R, Silverman H, Stanchina M, Vieillard-Baron A, Welte T. Weaning from mechanical ventilation. Eur Respir J. 2007;29(5):1033-56. https://doi.org/10.1183/09031936.00010 206.

25. Richard C, Teboul JL. Weaning failure from cardiovascular origin. Intensive Care Med. 2005;31(12):1605-7. https://doi.org/10.1007/ s00134-005-2698-x.

26. Caille V, Amiel JB, Charron C, Belliard G, Vieillard-Baron A, Vignon P. Echocardiography: a help in the weaning process. Crit Care. 2010;14(3):R120. https://doi.org/10.1186/cc9076.

27. Bataille B, Riu B, Ferre F, Moussot PE, Mari A, Brunel E, Ruiz J, Mora M, Fourcade O, Genestal M, Silva S. Integrated use of bedside lung ultrasound and echocardiography in acute respiratory failure: a prospective observational study in ICU. Chest. 2014;146(6):1586-93. https://doi.org/10.1378/chest.14-0681.

28. Silva S, Biendel C, Ruiz J, Olivier M, Bataille B, Geeraerts T, Mari A, Riu B, Fourcade O, Genestal M. Usefulness of cardiothoracic chest ultrasound in the management of acute respiratory failure in critical care practice. Chest. 2013;144(3):859-65. https ://doi.org/10.1378/chest.13-0167.

29. Pinsky MR. Breathing as exercise: the cardiovascular response to weaning from mechanical ventilation. Intensive Care Med. 2000;26(9):1164-6.

30. Asehnoune K, Seguin P, Lasocki S, Roquilly A, Delater A, Gros A, Denou F, Mahe PJ, Nesseler N, Demeure-Dit-Latte D, Launey Y, Lakhal K, Rozec B, Malledant Y, Sebille V, Jaber S, Le Thuaut A, Feuillet F, Cinotti R. Extubation success prediction in a multicentric cohort of patients with severe brain injury. Anesthesiology. 2017;127(2):338-46. https://doi.org/10.1097/aln.00000 00000001725.

31. Vallverdu I, Calaf N, Subirana M, Net A, Benito S, Mancebo J. Clinical characteristics, respiratory functional parameters, and outcome of a 2-h T-piece trial in patients weaning from mechanical ventilation. Am J Respir Crit Care Med. 1998;158(6):1855-62. https://doi.org/10.1164/ajrccm.158.6.9712135.

32. Peris A, Tutino L, Zagli G, Batacchi S, Cianchi G, Spina R, Bonizzoli M, Migliaccio L, Perretta L, Bartolini M, Ban K, Balik M. The use of point-of-care bedside lung ultrasound significantly reduces the number of radiographs and computed tomography scans in critically ill patients. Anesth Analg. 2010;111(3):687-92. https://doi.org/10.1213/ANE.0b013e3181e7cc42.

33. Bouhemad B, Liu ZH, Arbelot C, Zhang M, Ferarri F, Le-Guen M, Girard M, Lu Q, Rouby JJ. Ultrasound assessment of antibiotic-induced pulmonary reaeration in ventilator-associated pneumonia. Crit Care Med. 2010;38(1):84-92. https://doi.org/10.1097/ CCM.0b013e3181b08cdb.

34. Agricola E, Bove T, Oppizzi M, Marino G, Zangrillo A, Margonato A, Picano E. "Ultrasound comet-tail images": a marker of pulmonary edema: a comparative study with wedge pressure and extravascular lung water. Chest. 2005;127(5):1690-5. https://doi. org/10.1378/chest.127.5.1690.

35. Bedetti G, Gargani L, Corbisiero A, Frassi F, Poggianti E, Mottola G. Evaluation of ultrasound lung comets by hand-held echocardiography. Cardiovasc Ultrasound. 2006;4:34. https://doi. org/10.1186/1476-7120-4-34.

36. Coonar AS, Hughes JA, Walker S, dePerrot M, Waddell TK, Pierre AF, Darling GE, Johnston MR, Keshavjee S. Implementation of real-time ultrasound in a thoracic surgery practice. Ann Thorac Surg. 2009;87(5):1577-81. https://doi.org/10.1016/j.athor acsur.2008.12.024.

37. Neri L, Storti E, Lichtenstein D. Toward an ultrasound curriculum for critical care medicine. Crit Care Med. 2007;35(5 Suppl):S290-304. https://doi.org/10.1097/01.ccm.0000260680 .16213 .26 .

Publisher's Note Springer Nature remains neutral with regard to jurisdictional claims in published maps and institutional affiliations. 